\section{RELACIO $\wedge$ ES}

Relaciones. Estudios de historia y sociedad ISSN: 0185-3929

relacion@colmich.edu.mx

El Colegio de Michoacán, A.C

México

Ramírez Sevilla, Rosaura; Ledesma-Mateos, Ismael

La Commission Scientifique du Mexique: una aventura colonialista trunca

Relaciones. Estudios de historia y sociedad, vol. XXXIV, núm. 134, 2013, pp. 303-347

El Colegio de Michoacán, A.C

Zamora, México

Disponible en: http://www.redalyc.org/articulo.oa?id=13726972009

Cómo citar el artículo

- Número completo

- Más información del artículo

Página de la revista en redalyc.org

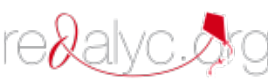

Sistema de Información Científica

Red de Revistas Científicas de América Latina, el Caribe, España y Portugal

Proyecto académico sin fines de lucro, desarrollado bajo la iniciativa de acceso abierto 


\title{
La Commission Scientifique du Mexique: una aventura colonialista trunca
}

\author{
Rosaura Ramírez Sevilla* \\ INSTITUTO POLITÉCNICO NACIONAL, ESIQUIE
}

Ismael Ledesma-Mateos

UNIVERSIDAD NACIONAL AUTÓNOMA DE MÉXICO, FES-IZTACALA

Este trabajo es un estudio de la Commission Scientifique du Mexique que se constituyó en París en febrero de 1864 por órdenes de Napoleón III y bajo la dirección de Víctor Duruy, ministro de Instrucción Pública del Imperio. La relevancia de esta investigación es que presenta la estructura y organización de la comisión, así como las biografías de sus miembros y un esbozo de las instrucciones que elaboraron para los viajeros que integraron su comisión exploradora. El trabajo considera el papel de las alianzas estratégicas en el desarrollo del conocimiento.

(Commission Scientifique du Mexique, Segundo Imperio Mexicano, intervención francesa)

éxico mantuvo durante el siglo XIX una relación comple-
ja, tortuosa con Francia: al darse su independencia busca
alejarse completamente de España y como contraparte, se acerca a la cultura francesa.

De hecho, la influencia de obras filosóficas francesas tuvo gran importancia en la inspiración de los insurgentes y en el ámbito cultural entre la época de la Ilustración y la Revolución de 1789, Francia fue el faro de los modelos políticos y sociales de la modernidad, París, convertida en "Ciudad Luz" era la capital mundial de la cultura, donde la gente debía ir para cultivarse y estar en el grado más alto de civilización. De este modo, las elites mexicanas prefirie-

*rosauraramirezsevilla@gmail.com prsmhct@gmail.com 
ron el afrancesamiento para acompañar la independencia, pudiendo así encaminarse hacia el progreso y alcanzar la civilización. ${ }^{1}$ Sin embargo, México era visto por Francia como un país con enormes riquezas naturales y una posición geopolítica estratégica en términos de su cercanía con los Estados Unidos de América, una nación poderosa en potencia.

\section{DE LA DEUDA EXTERNA MEXICANA A LA INTERVENCIÓN FRANCESA}

En 1861 al finalizar la guerra civil en México, en el ámbito internacional se dan las condiciones para la intervención extranjera. Por un lado, la Guerra de Secesión en Estados Unidos hace pensar a Napoleón III que ese país se desistiría de intervenir en cualquier sentido, por otro, el decreto de suspensión de pagos emitido por el presidente Juárez permite que se establezca una alianza entre Gran Bretańa, Espańa y Francia bajo el pretexto de salvaguardar los intereses de estas naciones y de sus particulares.

Al término de la guerra civil motivada por las Leyes de Reforma, la situación del país le impedía al Estado mexicano cumplir con sus compromisos económicos con el extranjero y el presidente Juárez emite el Decreto de Suspensión de Pagos el 17 de julio de 1861.

A partir de este momento, el imperio francés vislumbra la oportunidad de intervenir militarmente en el territorio nacional, fue así que para "el 31 de octubre ya se había firmado en Londres la convención que formalizó la alianza entre Espańa, Francia e Inglaterra para exigir la satisfacción de sus reclamaciones". ${ }^{2}$ Al llegar a las costas mexicanas, el gobierno de Juárez inicia negociaciones con los representantes de las tres naciones y logra que se firmen los Tratados de La Soledad

${ }^{1}$ Javier Perez-Siller, "Presentación: un tema, una perspectiva, una problemática”, en Javier Pérez-Siller, coord., México Francia. Memoria de una sensibilidad común. Siglos XIXXX, México, Benemérita Universidad Autónoma de Puebla, El Colegio de San Luis, Centro Francés de Estudios Mexicanos y Centroamericanos, 1998, 11-12.

2 Patricia Galeana, "México: codiciado botín 1861-1863" en Revista Mexicana de Política Exterior, nueva época, 40-41, México, Instituto Matías Romero de Estudios Diplomáticos, Secretaría de Relaciones Exteriores, 1993, 115-120. 
que significaron su reconocimiento por parte de las potencias invasoras, además de la disolución de la alianza tripartita, al acordarse la realización de convenciones bilaterales. España e Inglaterra decidieron retirar sus escuadras mientras Francia, que tenía un programa imperialista preconcebido, violó los acuerdos de la Convención de Londres [así] como los Convenios de La Soledad y avanzó sobre el país. ${ }^{3}$

Cuando los representantes del emperador francés emprenden la tarea de convencer a los españoles y a los ingleses de intervenir en el territorio mexicano en defensa de los intereses de sus connacionales, en lo que algunos autores llaman el "sueńo más ambicioso del imperio"

Napoleón III encuentra una ocasión para construir un proyecto grandioso: Él deseaba hacer de México una monarquía latina y católica, cliente de Francia que contrabalancearía a la potente y arrogante república de los Estados Unidos, protestante y anglosajona. Desde 1819, se extiende peligrosamente hacia el sur, pero por el momento está debilitada por la guerra de secesión. Se trata, entonces de aprovecharlo. ${ }^{4}$

$\mathrm{Al}$ retirar sus tropas tanto España como Inglaterra, "el 16 de abril (de 1862) sus representantes Alphonse Dubois de Saligny y Julián de la Gravière declaraban la guerra al gobierno de México. Su acción era desde todos los puntos de vista injustificable, ya que argumentaban que México había agredido a Francia con el decreto de suspensión de pagos ya abolido", 5 dando con ello inicio a la ocupación militar del territorio mexicano.

\section{El imperio de MaXimiliano}

En 1862, una vez consumada la intervención militar, el mando francés “formó entonces un grupo de 'notables', que decidió constituir a Méxi-

${ }^{3}$ Patricia Galeana, Idem.

${ }^{4}$ Eric Anceau, La France contemporaine: La France de 1848 a 1870. Entre ordre et mouvement, París, Librairie Générale Française, 2002.

${ }^{5}$ Patricia Galeana, "México: codiciado botín..., pp. 115-120. 
co como Monarquía Moderada y propuso para Emperador a Maximiliano, Archiduque de Austria, o a quien nombrara Napoleón III”. ${ }^{6}$

De 1862 a 1864, en Europa continúan las negociaciones de los conservadores mexicanos para traer a México un emperador en la persona de Maximiliano de Habsburgo, hermano del emperador austriaco Francisco José I, lo cual además permitiría a Napoleón III limar asperezas por el apoyo prestado a los nacionalistas italianos para recuperar los territorios que estaban bajo el control de Austria.

En 1863, los cálculos de Napoleón III en relación con la no intervención de los Estados Unidos se concretan cuando "El secretario de Estado, William H. Seward, manifestaba, paradójicamente, el respeto de su gobierno por la autodeterminación de los mexicanos: [...] Quedaba de manifiesto que dada su guerra civil, los norteamericanos no querían complicar su situación entrando en conflicto con Francia"?

El estudio del contexto en el que se desarrollan los eventos que constituyeron la intervención militar francesa, por un lado, y el ofrecimiento de la corona para la formación de una monarquía en México al príncipe Maximiliano de Habsburgo, da cuenta del cúmulo de contradicciones y falsas suposiciones a partir de las cuales se asume la conquista del territorio mexicano desde el punto de vista militar y, por otro, lo que para ellos es el desarrollo de un proyecto "civilizatorio", que como se dijo, algunos historiadores califican como el proyecto imperial mas ambicioso de Napoleón III. ${ }^{8}$ Un acontecimiento derivado de todo ello fue la creación de la Commission Scientifique du Mexique.

\section{El proyecto de Napoleón III y la movilización DEL MUNDO}

México -escribe M. Chevalier en 1846- "es un país admirablemente dotado por la naturaleza, la flora es la más rica y la más variada

${ }^{6}$ Juan Brom, Esbozo de Historia de México, México, Grijalbo, 2007.

7 Patricia Galeana, "Sueños imperiales", en Revista Mexicana de Política Exterior, nueva época, 42, México, Instituto Matías Romero de Estudios Diplomáticos, Secretaría de Relaciones Exteriores, 1994, 81-88.

${ }^{8}$ Eric Anceau, La France contemporaine... 
que se puede imaginar". "Sobre las laderas que se elevan gradualmente a partir de la costa" -explica, en 1851, l'Annuaire del DeuxMondes-

el viajero, en la medida que se aleja del mar, verá la sucesión de todos los climas, todas las riquezas naturales, desde la temperatura abrumadora del Senegal, hasta la primavera en la orilla del Sena, desde las producciones ecuatoriales, el café, la caña de azúcar, la vainilla, el cacao, el algodón, los platanares y la madera de tinte y de ebanistería, hasta el trigo de Europa, los olivos de España y de Italia y los abetos de los Alpes. ${ }^{?}$

En consecuencia, de acuerdo con Guy-Alain Dugast, a partir de la independencia de México, una imagen del país llega a Francia produciendo un verdadero mito político, el mito de la tierra mexicana: Le mythe mexicane, que fue una inspiración para ideas intervencionistas que se dieron en décadas posteriores. ${ }^{10}$

Las representaciones generadas al respecto de México, influenciaron la decisión de realizar la intervención francesa, como la grande pensée du règne de Napoleón III. ${ }^{11}$ Una aventura que implicaba apoderarse de tierras exóticas fácilmente dominables.

Es claro que la Intervención Francesa en México implica sin lugar a dudas una empresa colonialista. Luego de la consolidación del Segundo Imperio, Napoleón III se aboca a la pretensión de tomar el control de un país con características estratégicas que facilitarían la conversión de Francia en una gran potencia, de ahí que llamemos a este proceso "una aventura colonialista", la cual no llegó a consolidarse debido a la resistencia del gobierno de Juárez y la diferencia de perspectivas con el imperio de Maximiliano.

Al no poder incidir de forma plena en la toma de decisiones de Maximiliano, Napoleón III retira sus tropas y con ello también la Comission, creada para el conocimiento del territorio para su mejor explotación.

${ }^{9}$ Alain Dugast, La tentation mexicaine en France au XIXe siècle. L'image du Mexique et l'Intervention francaise (1821-1862), t. I, París, L'Harmattan, 2008, 158.

${ }^{10}$ Alain Dugast, La tentation mexicaine... t. II, p. 207.

${ }^{11}$ Alain Dugast, La tentation mexicaine... t. II, p. 209. 
El fenómeno colonialista implícito en la intervención francesa, posee características que lo distinguen de otros casos de colonialismo puesto que aquí se trata de una acción realizada a petición de grupos conservadores nacionales motivados por razones ideológicas y de intereses económicos, produciendo una acción concertada entre el clero y los grupos antiliberales planteando como premisa la entrega del gobierno a un miembro de la dinastía de los Habsburgo a la cual pertenecían los primeros monarcas españoles de la época de la Colonia.

Se trató de una alianza para frenar el avance liberal y convertir a México en una nación dominada por el catolicismo y los intereses reaccionarios. Esto no es comparable a los casos de colonialismo exitoso de la Gran Bretańa o de la misma Francia en otros territorios.

Sin embargo, lo que atrae nuestra atención no es el estudio de la intervención en sí misma, sino la manera en cómo ésta acopló un dispositivo científico como una forma de obtener el máximo provecho del territorio dominado, el cual poseía adicionalmente un halo de misterio similar al del antiguo Egipto para Napoleón Bonaparte. Asimismo, el proyecto implicaba el aseguramiento de un enclave monárquico y católico al sur de los Estados Unidos, joven república, anglosajona y protestante, así como la conversión de México en cliente de Francia.

No obstante, a diferencia de las acciones coloniales de Francia en otros territorios, en el caso de México se trataba de una nación cuyos antecedentes históricos la hacían sumamente atractiva, donde "civilizar" significa comprender para controlar.

El abordaje de la historia de este breve episodio colonialista, ha sido realizado desde perspectivas distintas a las de los intereses científicos en sentido estricto, por ejemplo, dejando de lado la trascendencia del desplazamiento, no sólo material, sino también simbólico, de la información derivada de las tareas de la Commission, de ahí la importancia de iniciar trabajos con esta orientación.

Considerando lo anterior, la idea de Bruno Latour acerca de la "movilización del mundo hacia los centros de concentración del conocimiento" resulta pertinente para este análisis, es decir, la manera en cómo por medio de la Commission Scientifique du Mexique se buscó desplazar la información necesaria para incorporar el saber de lo mexicano, que significa el conocimiento del país en sus diversos 
aspectos: recursos naturales, cultura, geografía, infraestructura, industria, etcétera, para incorporarlo a la ciencia francesa y la colonización del territorio, si las condiciones políticas, geográficas, económicas y culturales lo permitían dentro de la amalgama saber y poder.

Todo lo anterior se expresa como una red de actores humanos y no humanos, ${ }^{12}$ en este caso, emperadores, militares, políticos y sabios con minerales, razas, plantas, animales, climas, la presión atmosférica, los vestigios de antiguas culturas, el Istmo de Tehuantepec, etcétera.

Se trata de un emperador que utiliza su ejército y militares para una empresa que no es sólo invadir un territorio -e imponer a otro emperador-, sino conocerlo plenamente para consolidar un proyecto de dominio integral; políticos hábiles al servicio de esa causa, preocupación extrema por todo lo que puede llevar al éxito como el control de la riqueza mineral, vegetal y animal, el dominio de las razas, la comprensión de los climas, de los aspectos culturales.

Más adelante, en este mismo orden de ideas, los reportes de las actividades de la Commission, que fueron enviados a París para su publicación, tenían por cometido afianzar el resultado de la invasión, más allá de una ocupación militar. No es un simple traslado territorial, sino de la puesta en marcha de un proyecto que intenta llevar México a París, seccionándolo en campos disciplinarios estratégicos en forma de conocimiento científico, que serviría para controlar al nuevo espacio intervenido, lo cual no llegó a concretarse en un resultado final que implicara el uso pleno de los recursos naturales del territorio invadido con repercusiones en la industria y la economía francesas, ni en lo cultural produciendo nuevos esquemas ideológicos para el control del territorio colonizado, puesto que al interrumpirse la invasión estas actividades no tuvieron continuidad.

${ }^{12}$ En la línea de interpretación de Bruno Latour, donde entiende por movilización del mundo: desplazarse hacia el mundo, dotarlo de movilidad, encauzarse hacia los mundos controvertidos, protegerlo y adaptarlo para un uso discursivo. Es el caso de la historia de las expediciones iniciadas hace tres e inclusive cuatro siglos por todo el mundo y destinadas a recoger plantas, animales, rocas, trofeos y datos cartográficos. Para otras disciplinas, la palabra movilización designará instrumentos y equipamiento; para otras, encuestas o cuestionarios que reúnen información sobre el estado de una sociedad o de una economía. Bruno Latour, "Joliot: l'histoire et la physique mêlées", en Michel Serres, dir., Elements d'Histoire des Sciences, París, Bordas, 1989, 493-513. 


\section{DE COMISIONES Y COLABORACIONES}

Durante la intervención francesa, frecuentemente se confunde a dos comisiones: La Comisión Científica de México -Commission Scientifique du Mexique (CSM) - creada en París, por decreto de Napoleón III y otra, formada en México por iniciativa del General Bazaine, La Comisión Científica, Literaria y Artística de México -Commission Scientifique, Littéraire et Artistique du Mexique (CSLAM)-. Posteriormente se constituyó también la Academia Imperial de Ciencias y Literatura ${ }^{13}$ por órdenes del emperador Maximiliano de Habsburgo, que no será tratada en este trabajo.

Todo este proceso se da en el contexto de una profunda división en México entre los liberales y los conservadores, por su rechazo o aceptación de la intervención militar francesa, y de la proclamación de un nuevo imperio, pues paradójicamente, como se desprende del conocimiento de las biografías de muchos colaboradores del Imperio, aun siendo liberales o simpatizantes de ellos, se prestaron a participar en algunos de sus proyectos.

Para la distinción de ambas comisiones, se pueden identificar las publicaciones del siglo xIx que dan cuenta de las adhesiones a una $\mathrm{u}$ otra comisión, entre ellas están el Boletín de la Sociedad Mexicana de Geografía y Estadística y la Gaceta Médica de México, donde publican personajes afines a la Comisión Científica, Literaria y Artística de México. Por otro lado, debe enfatizarse que los trabajos de la Commission Scientifique du Mexique fueron publicados en París en los Archives de la Commission Scientifique du Mexique.

Se han realizado diversos trabajos acerca de la Commission Scientifique du Mexique, aunque en la mayoría aparece una presentación general de ella, debiendo mencionar en primer lugar el trabajo de M. Maldonado-Koerdell, ${ }^{14}$ y años después los de Alberto

${ }^{13}$ Service Historique de la Défense, G7 , 206, Diario del Imperio, 5 de julio de 1865, 14 .

${ }^{14}$ M. Maldonado-Koerdell, "La commission scientifique du Mexique, 1864-1869", en Memorias del Primer Coloquio Mexicano de Historia de la Ciencia, t. I, México, Sociedad Mexicana de Historia de la Ciencia y la Tecnología, 2-7 de septiembre de 1963, México, D. F. 1964, 239-247. 
Soberanis, ${ }^{15}$ Hugo Pichardo Hernández, ${ }^{16}$ Daniel Schavelzon,,${ }^{17}$ Luz Fernanda Azuela Bernal, ${ }^{18}$ Armelle Le Goff, ${ }^{19}$ Nadia Prevost ${ }^{20}$ y Juan José Saldaña. ${ }^{21}$

Antes de abordar los aspectos de nuestro interés al respecto de la CSM, es necesario señalar algunas cuestiones referentes a la CSLAM, a fin de evitar confusiones.

\section{La Comisión Científica, Literaria y Artística de MéXico}

\section{La Comisión Científica, Literaria y Artística de México (CSLAM) se} conformó mayoritariamente con personajes conservadores, miembros de la elite profesional e intelectual, así como liberales colabora-

${ }^{15}$ Alberto Soberanis, "La ciencia marcha bajo la égida de la guerra. Las relaciones científicas franco-mexicanas durante el imperio de Maximiliano (1864-1867)", en Revista Universidad de Guadalajara, Guadalajara, enero-febrero de 1995, 50-60; Alberto Soberanis, "La expansión geográfica de la ciencia. Orígenes históricos de la Commission Scientifique du Mexique", en Revista del Seminario de Historia Mexicana, Guadalajara, primera época, vol. 1, núm. 3, primavera de 1998, 9-75; Alberto Soberanis, "Sabios, militares y empresarios. Sansimonismo y exploración científica" en Javier Pérez-Siller y Chantal Cramaussel, coords., México-Francia: memoria de una sensibilidad común, siglos XIX-XX, vol. II, México, BUAP, CEMCA, El Colegio de Michoacán, 2004.

${ }^{16}$ Hugo Pichardo, "La Comisión Científica francesa y sus exploraciones en el territorio insular mexicano, 1864-1867”, en Política y Cultura, otońo, núm. 016, 2001.

${ }^{17}$ Daniel Schavelzon, "La Comisión Científica Francesa a México (1864-1867) y el inicio de la arqueología en América”, en Sacarina, Arqueología y Etnografía Americana, vol. 3, año III, noviembre 2003, 313-322.

${ }^{18}$ Luz Fernanda Azuela, "La Sociedad Mexicana de Geografía y Estadística, la organización de la ciencia, la institucionalización de la geografía y la construcción del país en el siglo XIX", en Investigaciones Geográficas, uNAM, México, diciembre, núm. 52, 2003, 153-166.

${ }^{19}$ Armelle Le Goff,"La Commission de l'exploration scientifique de Mexique: Quelles archives aux Archives nationales", Histoires(s) de l'Amerique Latine, vol. 3, 2009.

${ }^{20}$ Nadia Prévost, "Réévaluation de la 'Commission scientifique du Mexique' à travers les dépêches du colonel Doutrelaine", Colloque international "Mémoire(s) d'ici et d'ailleurs. Hommage à Ernest-T. Hamy (1842-1908)", C.E.R.C.L.E., HLLI, Université Du LittoralCôte d'Opale, Boulogne-sur-Mer, France, 2008; "La Commission Scientifique du Mexique (1864-1867): un exemple de collaboration scientifique entre l'élite savante française et mexicaine ?", en Revue d'Histoire des Sciences Humaines, Auxerre, núm. 19, 2008/2, 107 116; Commission de l'exploration scientifique du Mexique, F/17/2909 à 2914/3 (1862-1893). Répertoire méthodique et semi-analytique établi par Armelle Le Goff, conservateur en chef du patrimoine et Nadia Prévost Urkidi, docteur en histoire, París, Archives Nationales, 2009.

${ }^{21}$ Juan José Saldaña, “La ciencia y la política en México (1850-1911)”, en Ruy Pérez Tamayo, coord., Historia de la ciencia en México, México, FCE, conaculta, 2010, 120-199. 
cionistas, con intereses más bien "cortesanos" que científicos. De ella encontramos la mayor información en el periódico mexicano $E l$ Pájaro Verde que, por mencionar algunos ejemplos, en su número del 19 de abril de 1864, dice: "La Comisión científica, literaria y artística de México, debe instalarse solemnemente hoy a las 12 del día en la sala de Actos de la Escuela Imperial de Minas". ${ }^{22}$ Luego, el sábado 23 de abril, se publica el Discurso pronunciado por el S.E. el jeneral (sic) Bazaine en la solemne instalación de la Comisión Científica, Literaria y Artística el día 19 del corriente, donde nombra las especialidades incluidas en dicha comisión, a saber: Naturalistas, Geólogos, Mineralojistas [sic], Astrónomos, Geógrafos, Médicos, Agrónomos, Industriales y Comerciantes, Financieros y Economistas, Estadísticos, Historiadores, Arqueólogos, Arquitectos, Pintores, Escultores, Grabadores, Músicos y Artistas, ${ }^{23}$ y por último el miércoles 27 de abril se publica el discurso pronunciado por el subsecretario de Estado y del Despacho de Fomento, D. José Salazar Ilarregui, en el acto de la apertura de la Comisión Científica, Artística y Literaria de México. ${ }^{24}$ La composición de esta Comisión, queda registrada en los Archivos Nacionales de Francia en la sede de París. ${ }^{25}$

Un documento importante al respecto es el acta de la sesión celebrada el 30 de abril de 1864 en la Academia de Medicina de México, que a partir de esta fecha se conoció como la sección sexta de la Comisión Científica, Literaria y Artística de México, ${ }^{26}$ y que está integrada de la siguiente manera: Medicina, Cirugía, Higiene, Medicina veterinaria, Estadística médica, Materia Médica, Antropología, siendo su presidente el doctor Eichmann, médico en jefe. ${ }^{27}$ Por otro lado, la Gaceta Médica se ostentó desde 1864, en su primer número como Periódico de la Comisión Cientifica, y a partir del primero de enero de 1866 el subtítulo que aparece es el de Periódico de

\footnotetext{
${ }^{22}$ El Pájaro Verde, tomo II, núm. 236, 1864, 3.

${ }^{23}$ El Pájaro Verde, tomo II, núm. 240, 1864, 3.

${ }^{24}$ El Pájaro Verde, tomo II, núm. 242, 1864, 3.

${ }^{25}$ Archives Nationales (le site Paris) F/17/2909.

${ }^{26}$ El Pájaro Verde, tomo II, núm. 236, 1864, 3.

${ }^{27}$ Archives Nationales (le site Paris) F/17/2909.
} 
la Sociedad Médica. La conformación de esta sección sexta es de gran relevancia porque tuvo continuidad después de la caída del Imperio y por que da cuenta del carácter conservador de la comunidad médica de ese tiempo.

Si bien la CSLAM creada por el general Bazaine en México, está constituida por diez secciones, es un espejo de la CSM creada en París, pues los campos de conocimiento que propone son prácticamente los mismos, a excepción de las matemáticas y la mecánica (véase anexo 1). De los párrafos que el mariscal Vaillant lee en París el 14 de abril de 1864, el coronel Doutrelaine dice: "si no estamos en condiciones de hacer los trabajos científicos, podremos al menos hacer ciertas observaciones simples, reunir materiales de diversa naturaleza" ${ }^{28}$ Una de las diferencias entre ambas Comisiones, es que la formada en México, está constituida por militares franceses y algunos de los miembros de las sociedades científicas mexicanas, tanto la de geografía y estadística como la médica, así como algunos colaboradores de Maximiliano de Habsburgo. Así se explica por ejemplo que el programa de antropología elaborado por el $1 \mathrm{er}$. Comité de la Commission Scientifique du Mexique del que formaba parte M. el Barón Larrey, médico militar haya sido el mismo que retomó la $6^{\mathrm{a}}$. Sección de la Comisión Científica, Literaria y Artística de México.

\section{La Commission Scientifique du Mexique (csm)}

La creación de esta Commission emula la creada por Napoleón I para Egipto. En el documento elaborado para justificar su organización ellos dicen que

si bien México no les ofrece el interés histórico que representaba Egipto [...] hay seguramente secretos a descubrir: una civilización extrańa, que la ciencia deberá hacer revivir, las razas de las cuales se nos escapa su origen, las lenguas desconocidas, las inscripciones misteriosas y los monumentos

${ }^{28}$ Archives de la Commission Scientifique du Mexique. Publiés sus les auspices du Ministère d'Instruction Publique, t. I, París, Imprimerie Impériale, 1865, 176. 
grandiosos. [...] Una exploración verdaderamente científica abrirá ciertamente a esta industria un futuro inesperado. ${ }^{29}$

La CSM se formó en París en febrero de 1864, como parte de un proyecto más amplio que incluye el control político, militar y económico del territorio mexicano, y se integró por sabios, naturalistas, políticos y militares, todos ellos franceses, a diferencia de la CSLAM que se formó en la ciudad de México, como un contraproyecto en el que coinciden militares franceses -como Bazaine- con sabios y políticos mexicanos.

En una reunión el 4 de abril de 1864 en París, cuando el mariscal Vaillant da lectura a algunos fragmentos de una carta enviada por el coronel Doutrelaine, "en la que le comunica que en México se formará una Comisión parecida que será Franco-Mexicana”.$^{30}$ Fue en ese momento que la Comisión de París discute y se decide que las comisiones serán independientes.

De acuerdo a la información consultada, tanto en los Archivos Nacionales de Francia como en el Archivo Histórico de la Armada de Tierra en el Château de Vincennes, París, la tesis de la comunicación y colaboración entre los miembros de la Commission Scientifique du Mexique, y la incipiente comunidad científica mexicana de la segunda mitad del siglo XIX no se sostiene, en lo cual coincidimos con Nadia Prevost, quien analizando los comunicados oficiales del coronel ingeniero Doutreline se cuestiona si esa relación fue posible, concluyendo que existe una clara distancia entre ambas, e incluso puede percibirse una actitud de menosprecio. ${ }^{31}$

Efectivamente, hubo un contacto entre la CSM formada en París con la CSLAM formada en México por medio del coronel Doutrelaine, quien fue propuesto al emperador Napoleón III para ser nombrado como representante en México e intermediario, ${ }^{32}$ como por el

${ }^{29}$ Archives..., pp. 3-5.

${ }^{30}$ Archives..., p. 176.

${ }^{31}$ Nadia Prévost Urkidi, "La Commission scientifique du Mexique (1864-1867): un exemple de collaboration scientifique entre l'élite savante française et mexicaine?", en Revue d'Histoire des Sciences Humaines, Auxerre, núm. 19, 2008/2, 107-116.

${ }^{32}$ Archives..., p. 179. 
doctor Eichmann, presidente de la 6a Sección de la CSLAM, quien era además médico en jefe del ejército francés, relación que se mantuvo a través de M. el barón Larrey, miembro del 1er. Comité de la CSM, eso no significa que la CSLAM haya tenido una verdadera colaboración fluida con la CSM anclada en París y concebida con propósitos vinculados a los del Imperio europeo y no a los del naciente Imperio mexicano.

La Commission Scientifique du Mexique se constituye, por recomendación del Ministro de Instrucción Pública M. Víctor Duruy

para asegurar a la expedición científica todas las garantías de éxito [...] [que ésta este] compuesta de hombres eminentes en las ciencias y en el Estado, o de eminencias que han explorado ya la América central, esta comisión dará a los viajeros las instrucciones necesarias, seguirá el progreso de la expedición, y preparará, para el mundo sabio, la publicación de una obra que será, [...], un monumento digno del patrocinio que Vuestra Majestad se digne acordar para esta bella empresa. ${ }^{33}$

El 27 de febrero de 1864 se publica el decreto de Napoleón III dando instrucciones al Ministro de Instrucción Pública para preparar y organizar una expedición científica a México ${ }^{34} \mathrm{y}$ de seguir los resultados de ésta, el 2 de marzo se aprueba el reglamento sobre la organización de la comisión y en éste se fijan el objetivo y las áreas de interés de la empresa científica, a saber:

artículo $1^{\circ}$. La expedición científica tiene por objetivo un conjunto de estudios y de investigaciones propias a hacer conocer, desde todos los puntos de vista, a México y las regiones limítrofes. Art. $2^{\circ}$. Esta exploración se hará principalmente, sobre la geografía, la constitución geológica y mineralógica del país, la descripción de las especies animales y vegetales, el estudio de los fenómenos atmosféricos y de la constitución médica de las distintas razas, de sus monumentos, de su historia, etc. ${ }^{35}$

\footnotetext{
${ }^{33}$ Archives..., p. 7.

${ }^{34}$ Archives..., p. 12.

${ }^{35}$ Archives..., p. 10.
} 
En el documento que justifica la creación de la $\mathrm{CSM}^{,},{ }^{36}$ son notables tres vertientes: la primera, que se refiere a la emulación de los trabajos realizados en Egipto en los tiempos de Napoleón I; la segunda, la certeza de que no hay trabajos sobre México más destacables que los elaborados por el barón Alejandro de Humboldt, y que todo lo que se recabe deberá someterse a una rigurosa verificación científica; ${ }^{37}$ y la tercera, la gran curiosidad que les despertaba lo poco que conocían de México pero de cuya riqueza y diversidad tenían suficientes evidencias. Al estudiar la Commission debe resaltarse su configuración en sus diferentes Comités dependiendo del área de conocimiento que abordan.

La CSM queda constituida de la siguiente manera: presidente: Víctor Duruy, ministro de Instrucción Pública; mariscal Vaillant, ministro de Bellas Artes y representante del ministro de Guerra; barón Gros, senador, antiguo Embajador y antiguo ministro plenipotenciario en México; vicealmirante Juerien de la Gravière, antiguo comandante en jefe de las Fuerzas Navales de Francia en México; barón Larrey, miembro de la Academia Imperial de Medicina y miembro del Consejo de Salud de Guerra; Angrand, antiguo cónsul general en Guatemala; coronel Ribourt, jefe del gabinete del ministro de Guerra; Viollet-Leduc, arquitecto; César Daly, arquitecto; Marié-Davy, astrónomo del Observatorio Imperial; Bellaguet, jefe de la División del Ministerio de Instrucción Pública; así como por los sabios y científicos: Boussingault, Combes, Decaisne, Faye, de Longpérier, Maury, Milne Edwards, De Quatrefages, Charles Sainte-Claire Deville, de Tessan, Vivien de Saint-Martin Brasseur de Bourgbourg, Aubin, y es Anatole Duruy el secretario.

En la reunión del 10 de marzo de 1864 se acuerda su organización en cuatro Comités: ${ }^{38} 1$ er. Comité Ciencias Naturales y Médicas; 2do. Comité Ciencias Físicas y Químicas; 3er. Comité Historia, Lingüística y Arqueología, y 4o. Comité Economía Política, Estadística, Trabajos Públicos, Asuntos Administrativos.

\footnotetext{
${ }^{36}$ Archives..., p. 1-8.

${ }^{37}$ Archives..., p. 4.

${ }^{38}$ Archives..., p. 12-13.
} 
LOS MIEMBROS DE LOS COMITÉS, SUS BIOGRAFÍAS Y LAS INSTRUCCIONES SUMARIAS

Una vez organizada la Comisión en cuatro comités, los miembros de cada uno de ellos se dieron a la tarea de elaborar las Instrucciones sumarias para los viajeros, quienes se encargarían de hacer los estudios, mediciones, toma de muestras y recolectar los objetos de interés para cada uno de los comités, para garantizar con ello el valor científico tanto de los datos como de las colecciones, que constituye lo que anteriormente denominamos "la movilización del mundo".

\section{El Primer Comité: Ciencias naturales y médicas}

Los miembros de este comité son: Henri Milne Edwards, presidente; Jean-Louis Armand de Quatrefages, vicepresidente; Joseph Decaisne, Charles Sainte-Claire Deville y el barón Larrey, miembros.

Henri Milne-Edwards nació en 1800 en Brujas y muere en París en 1885 obtuvo el diploma de doctor en Ciencias Médicas en París. Abandona la práctica médica para dedicarse enteramente a las Ciencias Naturales, particularmente a la Zoología. Fue electo en 1838 miembro de la Academia de Ciencias, obtiene la cátedra de Entomología en el Jardín de las Plantas en 1841; en 1844 es nombrado profesor adjunto de Zoología y de Fisiología Comparada en la Facultad de Ciencias. En 1862 sucedió a Isidore Geoffroy Saint-Hilaire en la cátedra de mamíferos del Museo de Historia Natural y fue nombrado decano de la Facultad de Ciencias de París. Entre 1870 y 1885 fue editor de las Recherches zoologiques pour servir à l'histoire naturelle de la faune de l'Amérique centrale et du Mexique. ${ }^{39}$

Jean-Louis-Armand de Quatrefages de Bréau nació en Berthezenne el 10 de febrero de 1810 y muere en París en 1892. Fue ayudante preparador de Física y de Química en la Facultad de Ciencias de París; al mismo tiempo, investigaba en anatomía comparada.

${ }^{39}$ Patrick Tort, dir., Dictionaire du Darwinisme et de l'Evolution, vol. II, París, Presses Universitaires de France, 1996, 2957-2960; Nouvelle biographie générale, t. 35, 1861, 551-553. 
Recibe el diploma de doctor en matemáticas en 1830 y doctor en medicina en 1832, y en 1840 doctor en ciencias naturales. Antes, en 1838 es llamado a la Facultad de Toulouse para hacerse cargo del curso de zoología y renuncia a su clientela como médico. En 1852 es nombrado miembro de la Academia de Ciencias y en 1855 es llamado al Museo como profesor de Historia Natural del Hombre. Naturalista enciclopédico, fue también antropólogo, prehistoriador y estudioso de las razas humanas. ${ }^{40}$

Joseph Decaisne nació en Bélgica en 1807 y muere en París en 1882. Es un autodidacta que ingresa al Jardín de las Plantas como ayudante del jardinero ${ }^{41}$ y desde ahí alcanzará las más altas distinciones en el área de la Botánica, llegando incluso a presidir la Academia de Ciencias en 1865. Fundó la Sociedad Botánica de Francia. ${ }^{42}$

Charles Sainte-Claire Deville nació en las Antillas Danesas, en Santo Tomás en 1814 y muere en París en 1877, alumno de la Escuela de Minas de París, ingresa a los cursos preparatorios en 1835 y los abandona en 1838 cuando cursaba el tercer ańo, por lo que no obtiene el diploma de ingeniero civil de minas. Se dedica a la investigación de los fenómenos volcánicos y particularmente a aquellos sobre las emanaciones gaseosas, estudia también las variaciones de la temperatura en la atmósfera y el océano. Se vuelve asistente de Léonce Élie de Beaumont, a quien sucederá en la cátedra de Geología en el Colegio de Francia en 1855. En 1857 ingresa a la Academia de Ciencias, y en 1873 funda el Observatorio de Montsouris en París. ${ }^{43}$

Barón Félix-Hippolyte Larrey nació en París el 28 de septiembre de 1808 y muere en la misma ciudad el 8 de octubre de 1895 . Ingresa a Val-de-Grâce en 1828 donde obtiene el Doctorado en Medicina en 1832; es nombrado cirujano principal de 1 a Clase en 1839 y obtiene en 1841 la cátedra de Patología Quirúrgica en la Escuela de Medicina Aplicada y de Farmacia Militar de Val-de-Grâce. Ciruja-

${ }^{40}$ Patrick Tort, dir., op. cit., vol. III, p. 3588-3592; Nouvelle biographie générale, t. 41, $1862,275-277$.

${ }^{41}$ Patrick Tort, dir., op. cit., vol. I., p. 1148-1150.

${ }^{42}$ Dictionnaire de biographie francaise, t. x, p. 466.

${ }^{43}$ www.annales.org/archives/X/charlesdeville.html. 
no innovador, precursor del método antiséptico. En 1850 fue electo miembro de la Sección de Patología de la Academia de Medicina y de la Academia de Ciencias en 1867; en 1871 recibe la Legión de Honor y del Consejo de la Orden en $1877 .^{44}$

\section{Las instrucciones del Primer Comité}

En el Primer Comité se prepararon las instrucciones para Antropología, Zoología, Botánica, Mineralogía, Paleontología, Geología y Medicina.

En la introducción de estas Instrucciones, publicadas en los Archives de la Commission Scientifique du Mexique, los autores no omiten señalar la necesidad de colaboración entre las distintas ramas del conocimiento, y que deben enfrentar la realidad con dos puntos de vista: el puramente especulativo y un punto de vista práctico; por otro lado, hacen seńalamientos en el sentido de que a los viajeros sólo les compete hacer los estudios de naturaleza científica, es decir, sin buscar sus posibles aplicaciones.

En cuanto a las tareas concretas de los viajeros, se señala que no solamente harán los estudios necesarios in situ, sino además deberán recoger las muestras de los especimenes que constituirán las colecciones. El cuidado a estas colecciones varía según la naturaleza de sus objetos, y que cada especie animal o vegetal cada mineral y cada fósil, debe, en la medida de lo posible estar acompañado de algunas notas precisas, que representen por sí mismas una utilidad científica real. ${ }^{45}$

En las instrucciones particulares, los miembros del comité harán hincapié en los problemas particulares en los que se debe fijar la atención, sin menoscabo del celo, la iniciativa y la inspiración de los propios viajeros.

En este Comité las instrucciones se firmaron de manera conjunta, a diferencia de los otros comités donde cada autor firmó de manera individual.

${ }^{44}$ Nouvelle biographie générale, t. 29, p. 1091; Dictionnaire de biographie française, $\mathrm{t}$. XIX, p. 1089.

${ }^{45}$ Archives..., p. 20-21. 
Zoología. Los autores de estas Instrucciones, inician con una disertación sobre la riqueza de la fauna en México y América central, pero que aún no ha sido estudiada de una manera completa. Por tanto, los viajeros al encontrar gran número de nuevas especies, deberán ser estudiarlas en su conjunto, lo que será de gran importancia para el desarrollo de la Zoología Geográfica.

Indican la importancia de conocer también la fauna de los Estados Unidos y de la Nueva Granada, así como la de las dos vertientes de la Cordillera Mexicana y la fauna marina del Caribe y zonas adyacentes del Atlántico y del Pacífico, lo cual aportará resultados importantes para la zoología descriptiva. Los trabajos que los zoólogos de la Commission deberán realizar son de dos órdenes: el primero, relativo a la fauna marítima y, el segundo, a la fauna terrestre, fluvial y lacustre de México. ${ }^{46}$

Botánica. Los autores describen el paso de la botánica descriptiva a la botánica geográfica a partir del conocimiento de las relaciones entre la vegetación y los fenómenos geológicos cuya huella está sobre la superficie de la tierra. ${ }^{47}$

Debe resaltarse que el enfoque de estas dos últimas disciplinas, va más allá de lo descriptivo, propio de la Historia Natural imperante en la época, en este caso se busca la vinculación con el entorno geográfico con una orientación que dará lugar a la fitogeografía y la zoogeografía, y posteriormente a los estudios ecológicos.

Medicina. Los miembros del Comité declaran que para las ciencias médicas, México reclama de investigaciones numerosas y variadas, realizando un conjunto de preguntas generales y las indicaciones más precisas que abarcan temáticas que van desde cuestiones de historia de la medicina hasta la organización académica para su enseñanza, conocimiento de las enfermedades y los hábitats relacionados a ella, lo que se resume en el cuadro 1.

Finalmente se hace un largo listado de temas que pueden ser de interés, entre los cuales se encuentran aspectos relacionados con la higiene, los usos y costumbres en la alimentación y la atención a los partos.

\footnotetext{
${ }^{46}$ Archives..., p. 27-31.

${ }^{47}$ Archives..., p. 31-37.
} 
Las instrucciones sumarias elaboradas por el barón Larrey, médico militar y miembro de la Commission, son enviadas al general Bazaine y a los contralmirantes del Golfo de México y el Pacífico para ser tomadas en cuenta en los estudios que emprendan sobre las enfermedades que aquejan a las tropas francesas. ${ }^{48}$ Cabe señalar que cuando se elaboran las instrucciones para el área de la medicina existía comunicación entre los médicos militares asentados en México y el barón Larrey, médico militar miembro del comité. ${ }^{49} \mathrm{Tal}$ situación, sin embargo, no significa que haya existido colaboración entre las comisiones, sino sólo entre los militares con fines bélicos.

Por otro lado, los invasores se encontraron con un gremio -el de los médicos- dispuesto a cooperar con ellos, que contaba con un buen nivel de organización y con trabajos desarrollados en el sentido de los intereses tanto de la CSM formada en París como del cuerpo médico del ejército.

Geología y mineralogía. A partir del reconocimiento de la dificultad que entraña la elaboración de una carta geológica, los autores dicen que "se trata de recabar los datos generales sobre la constitución geológica del nuevo imperio mexicano, o si se quiere, de ampliar y completar aquellos de los que se tiene un pequeño número de observaciones". No será más que en casos particulares y para las regiones que presentaran un interés capital, sea desde el punto de vista de los fenómenos eruptivos, o sea desde el punto de vista de la geología estratigráfica o paleontológica, que se podría solicitar a los viajeros de la Comisión detenerse en los detalles y obtener cuidadosamente los rasgos locales. El estudio químico de las emanaciones volcánicas y la descripción de los restos orgánicos de los terrenos estratificados, ofrecerán en este sentido, el mismo interés, de una mina igualmente fecunda, porque ambos han sido hasta hoy apenas tocados en México. ${ }^{50}$

A partir del conocimiento de las instrucciones elaboradas por el Primer Comité, para dirigir los estudios y la recolección de muestras para las colecciones que se enviaron a Francia. Nos encontramos

\footnotetext{
${ }^{48}$ Archives..., p. 178.

${ }^{49}$ Archives..., p. 48-61.

${ }^{50}$ Archives..., p. 37-48.
} 
ante algo que va más allá de la simple acumulación de objetos, se trata de darles sentido, contenido, verbalidad, e integrarlos al conjunto de saberes institucionalizados en Europa, como parte de su propósito colonialista, y valiéndose de ello, contar con elementos para su pretendida "misión civilizatoria".

En el cuadro 1 se muestra un resumen de los principales intereses de cada una de las disciplinas que integraron el Primer Comité.

\section{Cuadro 1. Primer Comité: Ciencias Naturales y Médicas ${ }^{51}$}

Miembros: Henri Milne Edwards, presidente; Jean-Louis Armand de Quatrefages, vicepresidente; Joseph Decaisne; Charles SainteClaire Deville y el barón Larrey.

\begin{tabular}{ll}
\hline Disciplinas & Intereses \\
\hline Antropología & Fisiología y anatomía; \\
& Fisiología y anatomía \\
& comparada; razas indígenas, \\
& desaparición de ellas; razas \\
& extranjeras y su aclimatación. \\
& Colecciones: esqueletos, \\
& cabellos, bustos moldeados \\
& y coloreados, fotografías.
\end{tabular}

Zoología

Fauna marina del Caribe y zonas adyacentes del Atlántico y del Pacífico. Fauna terrestre, fluvial y lacustre (mamíferos, aves, reptiles, peces, moluscos, crustáceos, insectos gusanos y zoófitos)

Instrucciones

Para esta disciplina los autores de las Instrucciones plantean dos órdenes de preguntas "Generales", para el examen minucioso de todas las razas y "Especiales" que dividen a la población en tres grupos: indígenas, extranjeros y mestizos.

Indican la importancia de conocer la fauna de los Estados Unidos, de la Nueva Granada, y de las dos vertientes de la Cordillera Mexicana.

Botánica Géneros y especies en estado silvestre y cultivado, de ornato y de interés económico y maderable. Características ambientales

Los autores describen el paso de la botánica descriptiva a la botánica geográfica a partir del conocimiento de las relaciones entre la vegetación y los fenómenos geológicos cuya huella está sobre la superficie de la tierra.

${ }^{51}$ Archives..., p. 21-61. 


\begin{tabular}{lll}
\hline Disciplinas & Intereses & Instrucciones \\
\hline $\begin{array}{l}\text { Geología y } \\
\text { Mineralogía }\end{array}$ & $\begin{array}{l}\text { Vulcanología; estratigrafía; } \\
\text { minerales y minería }\end{array}$ & $\begin{array}{l}\text { Se trata de recabar los datos } \\
\text { generales sobre la consti- } \\
\text { tución geológica del nuevo } \\
\text { imperio mexicano, o de am- } \\
\text { pliar y completar aquellos de } \\
\text { los que se tiene un pequeńo } \\
\text { número de observaciones. }\end{array}$ \\
& & $\begin{array}{l}\text { Los miembros del Comité } \\
\text { Medicina }\end{array}$ \\
& $\begin{array}{l}\text { Historia de la medicina; } \\
\text { patología en diversas } \\
\text { altitudes; fiebre amarilla; }\end{array}$ & $\begin{array}{l}\text { de investigaciones numerosas } \\
\text { y variadas }\end{array}$ \\
& $\begin{array}{l}\text { Higiene; Medicina legal; } \\
\text { Geografía médica; Cirugía; }\end{array}$ & \\
& Materia médica; Academia & \\
\hline
\end{tabular}

\section{El Segundo Comité: Ciencias Físicas y Químicas}

Está formado por el mariscal Vaillant, presidente; vicealmirante Jurien de la Gravière, Boussingault, Combes, Faye, Doret de Tessan, Marié-Davy y Vivien de Saint-Martin.

Jean-Baptiste-Philibert Vaillant, mariscal de Francia, nace el 6 de octubre de 1790 en Dijon, muere el 16 de diciembre de 1872 en París. Ingresó a la Escuela Politécnica en 1807 y dos años más tarde fue admitido en la Escuela Aplicada de Artillería y de Ingeniería en Metz. Después de una larga carrera militar, ingresa al Senado el 26 de enero de 1852, y a finales de diciembre deviene gran mariscal del Palacio del Emperador hasta 1859. En 1853 es electo miembro de la Academia de Ciencia, ministro de Guerra de marzo de 1854 a mayo de 1859, y el 7 de septiembre de 1854 es puesto a la cabeza de la comisión instituida para recopilar, ordenar y publicar la correspondencia de Napoleón I. De 1857 a 1870 preside el Consejo General de la Côte d'Or. En 1860 el retoma el cargo de gran mariscal del Palacio, deviene ministro de la Casa del Emperador, y después en 1863 ministro de Bellas Artes. ${ }^{52}$

\footnotetext{
${ }^{52}$ Jean Tulard, dir., Dictionnaire du Second Empire, París, Fayard, 1995, 1296.
} 
Jean Pierre Edmond Jurien de la Gravière, vicealmirante. Nace el 19 de noviembre de 1812 en Brest y muere el 4 de marzo de 1892 en París. Ingresó en la Armada en 1828, llegando a comandante en 1841 y capitán en 1850 . Durante la Guerra de Crimea, comandó un buque por el Mar Negro. Fue ascendido a vicealmirante el 1 de diciembre de 1855 y nombrado para tomar el mando de un escuadrón en el Mar Adriático en 1859. En octubre de 1861 comandó un escuadrón en el Golfo de México y dos meses más tarde, la expedición contra México. Durante la Guerra Franco-Prusiana en 1870, comandó la flota francesa del Mediterráneo. Fue autor de una voluminosa obra sobre historia naval, además de escribir su biografía. Entre sus escritos más notables destaca Guerres maritimes sous la république et sous l'empire; La Marine d'autrefois (1865) y La Marina d'Aujourd'hui (1872). En 1888 fue elegido miembro de la Academia Francesa. ${ }^{53}$

Jean-Baptiste Boussingault nació en París el 1 de febrero de 1801 y muere en la misma ciudad el 11 de mayo de 1887. En 1819 ingresa a la Escuela de Minas de San Esteban donde es elegido como preparador de Química. Estuvo diez años en América del Sur, donde desarrolla los oficios de químico, director de minas, naturalista, geólogo, topógrafo, oficial adjunto al estado mayor de Bolívar. En 1839 reemplaza a Huzard en la Academia de Ciencias, suple a Dumas en la Sorbona y obtiene la cátedra de Agricultura en el Conservatorio de Artes y Oficios. Fue electo representante del Departamento del Bajo Rhin a la Asamblea Constituyente sentándose entre los republicanos moderados. Ingresa al Consejo de Estado formando parte de la sección legislativa, de donde sale el 2 de diciembre de 1851, y regresa a su puesto de enseñante. ${ }^{54}$

Charles-Pierre-Mathieu Combes nació en Cahors el 26 de diciembre de 1801 y muere el 11 de enero de 1872 en París. En 1820 ingresa a la Escuela de Minas donde pasa dos años en lugar de tres. Fue nombrado en 1823, profesor de Matemáticas, de Mecánica Aplicada, y de Levantamiento de Planos en la Escuela de Mineros

${ }^{53}$ Jean Tulard, dir., Dictionnaire..., p. 525.

${ }^{54}$ Dictionnaire de biographie française, t. vII, p. 32 
de San Esteban. Desarrolla su carrera en la Dirección de Minas y en 1832 se encarga de la Cátedra de Explotación de la Escuela de Minas de París; a partir del 4 de abril de 1857, asumirá la dirección de la escuela. En 1847 ingresa a la Academia de Ciencias en la sección de mecánica, fue secretario y después presidente, a partir de 1851 de la comisión de máquinas de vapor, miembro de la Comisión de Invenciones Relativas a los Caminos de Fierro, de la Sociedad de Fomento para la Industria Nacional, y de la Sociedad Central de Agricultura en la sección de Mecánica Agrícola. ${ }^{55}$

Hervé Étienne Auguste Albans Faye nace en 1814 y muere en 1902. Egresado de la Escuela Politécnica en 1832. Trabaja en la observación de los meridianos bajo la dirección de Arago en el Observatorio en 1842. En 1843, descubre un cometa de corto periodo, al que estudia Fayet en 1905, y obtiene el premio Lalande de la Academia de Ciencias. Estudia el movimiento propio de las estrellas e inventa la lente y el colimador zenital. Es electo a la Academia de Ciencias, miembro de la oficina de longitudes; obtiene el curso de Geodesia en la Escuela Politécnica de 1848 a 1854, y la cátedra de Astronomía en la Facultad de Ciencias de Nancy. Desafía al sistema cosmogónico de Laplace y considera al sol como una máquina térmica. Vicepresidente en 1871 de la Academia de Ciencias y presidente en 1872. Ministro de Instrucción Pública en $1877 .{ }^{56}$

Louis Urbain Dortet de Tessan nació en 1804 y murió en 1879. Ingeniero hidrógrafo. Reconoce las costas de Argelia para lo que idea un método de medición. Metereólogo de la misión Dupetit-Thouars, hace la vuelta al mundo hacia el oeste de 1836 a 1839. En 1849, es enviado a Bordeaux para inspeccionar la posibilidad de construir un nuevo puente sobre la Gironde; hace el reconocimiento hidrográfico del estrecho de Gibraltar y estudia las costas de la Mancha, hace los sondeos en la Bahía de Cherbourg en 1850. Retirado como Ingeniero de 1a Clase. Es electo correspondiente y después miembro en 1861 de la Academia de Ciencias en la sección de Geografía. ${ }^{57}$

${ }^{55}$ Dictionnaire de biographie française, t. Ix, p. 363-364.

${ }^{56}$ http://bibli.polytechnique.fr.

${ }^{57}$ http://bibli.polytechnique.fr. 
Hiplolyte Édme Marié-Davy nace en Clamecy, Nièvre, en 1820, y muere en Dornecy, Nièvre, en 1893. Astrónomo y físico, titular del Observatorio Imperial de París en 1862, se dedicó al estudio del geomagnetismo y de los movimientos de la atmósfera. Continúa los trabajos meteorológicos iniciados por E. Liais entre 1854 y 1856, organiza una red de observación de huracanes y la centralización de los informes de las estaciones meteorológicas locales; la difusión vía telegráfica de los boletines diarios (presión atmosférica, temperatura, dirección del viento, etcétera). De 1873 a 1887 ocupó la dirección del Observatorio Municipal de Montsouris, amplió su actividad al estudio de la composición química del aire, del suelo y de las aguas, con cuyos trabajos se fundó el Laboratorio de Higiene de París, además inventó una pila de bisulfato de mercurio. Publicó un atlas de los movimientos generales de la atmósfera y un atlas de huracanes. ${ }^{58}$

Louis Vivien Saint-Martin de Fontenay nace en Calvados, en 1802, muere en París, en 1897. Geógrafo francés. Estudioso de Historia y Geografía, escribió numerosas obras, entre ellas El Norte de África en la antigüedad griega y romana (1863), Historia de la geografia y de los descubrimientos geográficos (1873). Inició un Atlas universal de geografia (1876), que fue concluido por F. Schrader en 1905.

\section{Las instrucciones del Segundo Comité}

A diferencia del primer comité, este aborda la elaboración de las instrucciones de manera individual, y son firmadas por cada uno de sus autores. Llama la atención el énfasis puesto en los recursos naturales no renovables, como son los metalíferos y de otros yacimientos minerales, lo que se encuentra estrechamente vinculado con intereses económicos.

Geografia. De acuerdo con Doret de Tessan, autor de las instrucciones de esta sección, en aquel momento, debido a la geografía general, no se podía exigir a los viajeros sino los trabajos más simples y más fáciles, los estrictamente necesarios para poder obtener un buen partido de los que se habían hecho con anterioridad. Agrega que

${ }^{58}$ http://cths.fr/an/prosopo.php Consultado el 10 de febrero de 2011. 
algo importante sería determinar con exactitud la latitud de la ciudad de México, para con ello proporcionar la base de "una gran triangulación geodésica" ${ }^{59}$

Hidrografia. De esta sección, aparece una "Nota sobre la exploración hidrográfica de las costas de México", firmada por el vicealmirante Jurien de la Gravière, donde hace algunas acotaciones sobre el estado que guarda el conocimiento de las costas mexicanas y dice:

Las costas de México sobre los dos océanos, no han sido objeto, en cierta medida de reconocimiento hidrográfico. Los planos particulares de los puertos principales han sido levantados con más o menos detalle, de hecho, trabajos en conjunto, no se tienen más que los antiguos mapas espańoles con algunas observaciones más recientes. ${ }^{60}$

Asimismo, dice que cualquier trabajo que se realice será de gran ayuda para la navegación, y que deberán identificarse los puntos principales, relacionándolos por medio de observaciones cronométricas con uno o dos puntos de primer orden donde las posiciones geográficas absolutas serían fijadas por las observaciones astronómicas. Y agrega, "se pueden emplear los métodos más o menos expeditos, abreviar o prolongar los reconocimientos secundarios, aquello que parece indispensable, esto es una exploración de conjunto que abarca la totalidad del litoral. Sin esta exploración, es casi imposible tomar ventaja de los documentos aislados que ya tenemos" ${ }^{61}$

Exploración de los yacimientos metalíferos y otras substancias minerales empleadas en la construcción y en la industria. Estas instrucciones las firma Charles Combes. Trata de los yacimientos de substancias minerales útiles que deben ser consideradas y estudiadas desde tres puntos de vista: geológico, histórico, técnico y económico, y dice: "Las principales minas de metales preciosos de México son ya conocidas por las obras de Alejandro de Humboldt, de Bukart, de SaintClaire Duport, por los resúmenes insertos en el Mining-journal de las

\footnotetext{
${ }^{59}$ Archives..., p. 75.

${ }^{60}$ Archives..., p. 77-78.

${ }^{61}$ Archives..., p. 78.
} 
operaciones de las compañías inglesas que han hecho la explotación de algunas de ellas, y por las obras españolas publicadas en México, entre otras las de Bustamante". ${ }^{62}$

El trabajo que se planteó el Segundo Comité fue monumental ya que suponían que "no había nada hecho en el país" por el nivel de atraso que le asociaban; reconocían como únicos trabajos válidos los elaborados por Humboldt. Finalmente, por el poco tiempo que duró tanto la intervención como el imperio, no fue posible sistematizar la información recabada.

A continuación se resumen en el cuadro 2, los principales objetos de interés del Segundo Comité.

\section{Cuadro 2. Segundo Comité: Ciencias Físicas y Químicas ${ }^{63}$}

Miembros: mariscal Vaillant, Jean-Baptiste-Philibert, presidente; vicealmirante Jurien de la Gravière; Boussingault, Jean-Baptiste; Combes, Charles-Pierre-Mathieu; Faye, Hervé Étienne Auguste Albans; Dortet de Tessan, Louis Urbain; Marié-Davy y Vivien de Saint-Martin.

\begin{tabular}{|c|c|c|}
\hline $\begin{array}{l}\text { Disciplinas o } \\
\text { Actividad }\end{array}$ & Objetos & Instrucciones hechas por: \\
\hline Orografía & $\begin{array}{l}\text { Vertientes Golfo Pacífico, } \\
\text { cordilleras, altitudes, límites, } \\
\text { variaciones climáticas, cadenas } \\
\text { secundarias, subdivisión de zo- } \\
\text { nas frías, templadas y calientes }\end{array}$ & $\begin{array}{l}\text { Mariscal Jean-Baptiste- } \\
\text { Philibert Vaillant. }\end{array}$ \\
\hline
\end{tabular}

Hidrografía Corrientes de agua, direc- Vicealmirante Jurien de la ción, dimensiones, naturaleza Gravière del suelo y vegetación. Ríos y arroyos. Costas. Vientos reinantes. Estación de lluvias. Estación seca, electricidad atmosférica, época de tormentas y huracanes. Fenómenos volcánicos, temblores de tierra.

\footnotetext{
${ }^{62}$ Archives..., p. 78.

${ }^{63}$ Archives..., p. 62-84.
} 


\begin{tabular}{|c|c|c|}
\hline $\begin{array}{l}\text { Disciplinas o } \\
\text { Actividad }\end{array}$ & Objetos & Instrucciones hechas por: \\
\hline Geografía & $\begin{array}{l}\text { Observaciones de la noche; } \\
\text { Estrella polar; Culminaciones } \\
\text { lunares, latitud de la ciudad } \\
\text { de México. Es lo que el autor } \\
\text { considera posible hacer. }\end{array}$ & $\begin{array}{l}\text { Louis Urbain Doret de } \\
\text { Tessan. }\end{array}$ \\
\hline $\begin{array}{l}\text { Explora- } \\
\text { ción de los } \\
\text { yacimientos } \\
\text { metalíferos y } \\
\text { otras substan- } \\
\text { cias minerales } \\
\text { empleadas en } \\
\text { la construc- } \\
\text { ción y en la } \\
\text { industria }\end{array}$ & $\begin{array}{l}\text { Aspecto geológico: Situ- } \\
\text { ación geográfica, dirección } \\
\text { de los filones, inclinación, } \\
\text { composición mineralógica, } \\
\text { estructura de los yacimientos, } \\
\text { relaciones con rocas adyacen- } \\
\text { tes. Aspecto Histórico: pro- } \\
\text { cedimientos de explotación, } \\
\text { tratamientos metalúrgicos, } \\
\text { historia de la legislación de } \\
\text { minas. Aspecto técnico: tem- } \\
\text { peratura del aire y de la roca a } \\
\text { diferentes niveles; preparación } \\
\text { de minerales; fábricas metalúr- } \\
\text { gicas; métodos de tratamiento; } \\
\text { planos de fábricas; dibujos de } \\
\text { hornos, vías de comunicación; } \\
\text { combustibles; agentes de } \\
\text { tratamiento. Aspecto comer- } \\
\text { cial: consumo, regulación de } \\
\text { salarios de obreros, régimen } \\
\text { alimenticio, estilo de vida, } \\
\text { hábitos; origen y precio de } \\
\text { insumos consumidos madera; } \\
\text { comercialización de minerales. }\end{array}$ & $\begin{array}{l}\text { Firmado por Charles } \\
\text { Combes }\end{array}$ \\
\hline
\end{tabular}

\section{El Tercer Comité: Historia, Lingüística y Arqueología}

Integrado por el barón Gros como presidente; Prévost de Longpérier; Maury, Angrand, Viollet-Leduc Daly; Brasseur de Bourboug y Aubin.

Barón Jean-Baptiste-Louis Gros. Diplomático, nació en Ivrysur-Seine el 8 de febrero de 1793 y muere en París el 17 de agosto de 1870. Ingresa a la diplomacia en 1823 , y deviene adjunto libre en la 
legación de Lisboa el 11 de julio. En 1831 es el secretario de la Legación en México, y en 1838 encargado de negocios en Bogotá. ${ }^{64}$

Henri-Adrien Prévost de Longpérier nació el 21 de septiembre de 1816 en París y muere en 1882. Su padre era alcalde de Meaux, le da una educación totalmente dedicada a los clásicos. Ingresa como supernumerario en los Imprimés en 1835; pero es la numismática su verdadera pasión, se incorpora al gabinete de medallas de la Biblioteca del Rey el ańo siguiente. En 1847 remplaza a M. Dubois en el puesto de conservador adjunto del Museo de Egipto, el año siguiente el asume como conservador titular. Desde entonces es responsable del Museo Asirio, el Museo Mexicano y la escultura antigua. Es miembro de la Sociedad de Anticuarios (1837), de la Academia de las Inscripciones (1854). Publica dos memorias sobre numismática, ambas con reconocimiento del Instituto. ${ }^{65}$

Louis-Ferdinand-Alfred Maury nació en Meaux el 23 de marzo de 1817 y muere en París el 11 de febrero de 1892. Fue adjunto en 1836 en la Biblioteca Real, misma que dejó dos años después para estudiar medicina y derecho. Llamado a la Biblioteca Real en 1840, pasó en 1844 a la del Instituto como sub-bibliotecario, habiendo publicado el año anterior un "Ensayo sobre las leyendas piadosas de la edad media", donde examina aquello que ellas encierran de maravilloso. Desde esta época, las religiones y los diversos fenómenos fisiológicos, intelectuales y morales que se relacionan con este orden de ideas son el objeto principal de sus estudios y de sus publicaciones. ${ }^{66}$

Léonce Angrand nació en París 1808 y murió en la misma ciudad el 11 de marzo 1886. Debuta en la carrera diplomática como secretario particular de Bertin de Vaux, enviado por Luis Felipe como embajador con el rey de los Países Bajos. Entre 1831 y 1856 se desempeña como representante diplomático en diversos países del orbe. Recorre la América hispana con un espíritu de observación

${ }^{64}$ Dictionnaire de biographie francaise, t. XvI, pp. 1315-1316.

${ }^{65}$ Nouvelle biographie générale, $\mathrm{t} . \mathrm{xxxI}$; Le cabinet des médailles de la bibliotheque nationale, 1661-1848, Thierry Sarmant, p. 286.

${ }^{66}$ Nouvelle biographie générale, $\mathrm{t}$. xxxiv. 
curiosa, reunió documentos etnográficos adquiriendo en esta materia una particular competencia. ${ }^{67}$

Eugène Emmanuel Viollet-Le-Duc nació el 27 de enero de 1814 en París y murió en la ciudad de Laussanne el 17 de septiembre de 1879. Arquitecto, estudioso del estilo gótico. Su formación tiene largos periodos autodidactas, de estancias en talleres y viajes por Francia que le permiten tener un conocimiento del patrimonio monumental francés muy superior al de sus contemporáneos y su documentación en dibujos y acuarelas. En 1834, es nombrado profesor suplente en el curso de composición de ornamentos en la Escuela gratuita de dibujo que se convertirá más tarde en la Escuela de Artes Decorativas. La obra de Viollet-Le-Duc gira en torno a tres ejes: el primero, es a favor del gótico; el segundo, concierne a la enseñanza de la arquitectura; y el tercero es el combate por el renacimiento de las artes decorativas. ${ }^{68}$

César-Denis Daly nació en Verdun el 19 de julio de 1811 y murió en París el 12 de enero de 1893. Ingresa a la escuela Politécnica de Douai y estudia arquitectura, se ocupa también de cuestiones sociales y se hace propagandista de las ideas de la Falange. En 1848, funda una sociedad de artistas decoradores que se dan como misión la de fomentar las preocupaciones artísticas en la producción industrial. A partir de 1850, llevó a cabo viajes por toda Europa, visita el norte de América, Egipto, Palestina, Turquía y el Asia menor, y trae de estos países numerosos dibujos de arquitectura. ${ }^{69}$

Charles-Étienne Brasseur de Bourbourg nació en Bourbourg el 8 de septiembre de 1814 y muere en Nice el 2 de junio de 1874 . Ingresa al seminario, viaja y es ordenado en Roma en 1845 y parte a Québec donde enseña historia eclesiástica. En 1854 se establece en América central con el título de administrador eclesiástico de los indios de Rabinal. Elabora "La historia de las naciones civilizadas de México y de América central”, en cuatro volúmenes 1857-1859, e inicia la publicación de una "Colección de documentos en lenguas

${ }^{67}$ Dictionnaire de biographie francaise, t. II, pp. 1236-1237.

${ }^{68}$ Dictionnaire du Second Empire, pp. 1317-1319.

${ }^{69}$ Dictionnaire de biographie francaise, t. X., p. 18. 
indígenas para servir al estudio de la historia y de la filología de la América antigua”, en tres volúmenes que aparecen entre 1861 y 1864 , pero sus conclusiones no son admitidas por los filólogos. Inicia enseguida "Monumentos antiguos de México", "Estudios sobre las ruinas de Palenque", "Cuatro cartas sobre México", relativas al sistema jeroglífico mexicano. Sus trabajos le valieron para ser nombrado miembro de la comisión científica, acompañando al ejército francés a México, él esperaba obtener en el Colegio de Francia una cátedra de Filología y de Arqueología Americana, experimenta una profunda amargura por el rechazo que le hacen en $1872 .^{70}$

Joseph-Marius-Alexis Aubin nació en Tourettes-les-Fayences el 18 de julio de 1812, muere en Calliant el 7 de julio de 1891. Llega a París en 1812 y durante sus estudios obtiene notables progresos sobre todo en dibujo y matemáticas, ingresa en 1816 a la Escuela de Bellas Artes y egresa con el primer lugar. Nombrado tutor en la escuela de dibujo y de matemáticas de 1815 a 1818, ingresa a la Escuela Normal Superior de donde saldrá en 1822, recibe en 1826 la dirección de la sección de ciencias de la Escuela Normal Superior, donde se quedará hasta 1830, toma parte en el movimiento revolucionario y combate al lado de Littré y de Georges Farcy. Parte para México en 1830, con fines de investigaciones físicas y astronómicas, pero los accidentes lo privarán de sus instrumentos de observación, compensará el no poder hacer sus estudios científicos con el examen e investigación de los monumentos antiguos. Vivió en México de 1830 a 1840 donde fundó un colegio que tuvo un éxito brillante. Compró gran número de documentos relativos a la historia de los antiguos mexicanos, manuscritos figurativos sobre papel indígena o europeo, y libros impresos en el país. Muchos de estos objetos le fueron proporcionados por eclesiásticos o sabios y provenían de los conventos de México. ${ }^{71}$

De este comité más que instrucciones los documentos que generaron fueron escritos donde plasmaron el conocimiento que tenían sobre México y sus ancestros, bajo el título de Bocetos de historia,

${ }^{70}$ Dictionnaire de biographie francaise. t. vII., p. 162.

${ }^{71}$ Dictionnaire de biographie francaise, t. IV, p. 209-210. 
arqueología, etnografía y de lingüistica, así como una Nota firmada por César Daly, que podría servir "para la exploración de monumentos antiguos de México". ${ }^{72}$

Este Comité posee un significado especial, dado que se ocupa de aspectos directamente vinculados con el llamado "mito mexicano": lo extrańo, lo mágico y enigmático cobran una enorme relevancia, que implicará el estudio de todas las facetas del México antiguo y muestran cierta similitud con la empresa de Napoleón Bonaparte en Egipto.

En el cuadro 3 se muestran los documentos elaborados como consecuencia de su trabajo y algunas observaciones.

\section{Cuadro 3. Tercer Comité: Historia, Lingüística y Arqueología ${ }^{73}$}

Miembros: Jean-Baptiste-Louis Gros, presidente; Charles-Étienne Brasseur de Bourourg; César-Denis Daly; Eugène Emmanuel Viollet-Le-Duc; Léonce Angrand; Louis-Ferdinand-Alfred Maury; Henri-Adrien Prévost de Longpérier; Joseph-Marius-Alexis Aubin.

\begin{tabular}{lll}
\hline Documento & Autor & Observaciones \\
\hline $\begin{array}{l}\text { Bocetos de historia, } \\
\text { arqueologia, etno- } \\
\text { grafia y de lingüistica }\end{array}$ & Abad Brasseur de & A partir de la visita del abad \\
& & Brasseur de Bourbourg a \\
& México, miembro del Tercer \\
& $\begin{array}{l}\text { Comité, se obtuvieron las } \\
\text { piezas arqueológicas que ahora } \\
\text { se exhiben en los museos } \\
\text { franceses. }\end{array}$
\end{tabular}

Bocetos de historia, Jean-Baptiste-Louis Información destinada a los arqueología, etno- Gross grafia y de lingüistica viajeros que habrán de estudiar los monumentos antiguos situados en los alrededores de la ciudad de México.

Nota César Daly

Podría servir para la exploración de monumentos antiguos de México.

${ }^{72}$ Archives..., p. 85-161.

${ }^{73}$ Archives..., p. 84-166. 
Cuarto Comité: eConomía política, estadística, TRABAJOS PÚBLICOS Y CUESTIONES ADMINISTRATIVAS

Sus integrantes fueron Michel Chevalier, presidente y Bellaguet, como miembro.

Michel Chevalier nació en Limoges, el 13 de enero de 1806 y muere el 28 de noviembre de 1879, en su castillo de Montplaisir. Ingresó en la escuela politécnica en 1823, de donde salió en 1825 como alumno de la Escuela de Minas. Su primer trabajo como ingeniero de minas fue en el departamento del norte, en el mes de noviembre de 1830 él renuncia para dedicarse completamente a la propaganda sansimoniana y convertirse en redactor en jefe del periódico El Globo. Después de un periodo de gracia y de éxito, los malos días llegaron para esta escuela. Publicó en el Globo algunos trabajos que habían atraído la atención de los conocedores, incluyendo un libro titulado $E l$ sistema del Mediterráneo, sorprendente por la audacia y precocidad de sus opiniones. En un momento en que el ferrocarril estaba en su estado naciente, Michel Chevalier osó recomendar la ejecución de una red que cubriendo todos los países ribereños del Mediterráneo y la conexión a Rusia, a Turquía, al Oriente y hubo incluso una propuesta para la perforación del istmo de Suez y Panamá. En este trabajo inicial ya está demostrando un credo económico al que Michel Chevalier permaneció fiel durante toda su vida: la fe en las obras públicas, en la penetración pacífica de los pueblos a través del comercio, a través del intercambio de productos. Retirado a la vida privada por los sucesos de 1870, él continúa su camino en el Colegio de Francia hasta $1878 .^{74}$

François-Louis Bellaguet nació en Sens en 1807, muere en 1887. Fue profesor del colegio Rollin, después en el colegio real de Saint-Louis, en París, entra al ministerio de Instrucción Pública hacia 1840 , donde es subjefe y después jefe de Bibliotecas. Jefe de la oficina de la cuarta división (institutos, sociedades y bibliotecas), de 1864 a 1871 fecha en la que el retiró de la actividad pública. ${ }^{75}$

${ }^{74}$ Jean-Pierre Callot, "Les polytechniciens et l'aventure saint-simonienne" en http:// www.annales.org/archives/x/saintsimonisme.html

${ }^{75}$ Dictionnaire de biographie francaise, t. v., p. 1312-1313. 
Este Comité se ocupa del conocimiento de las riquezas y recursos naturales de México; no se formularon instrucciones, en vez de ellas, se elaboró un documento con las siguientes secciones: Agricultura, Industria Manufacturera, Comercio, Arquitectura y trabajos públicos, Estadística. El documento da cuenta del interés por los minerales preciosos, fibras naturales, granos y las características del clima, las costumbres etcétera, que el emperador francés y sus científicos exploraban. En ese momento, si bien las tropas francesas ocupaban una parte importante del territorio nacional, no fueron capaces de haber pacificado al país, lo cual se erigió en un problema para ser recorrido por los exploradores franceses que debían ejecutar las instrucciones.

En el siguiente cuadro se resumen los principales objetos de interés de este Comité.

Cuadro 4. Cuarto Comité: Economía Política, Estadística, Trabajos Públicos y Cuestiones Administrativas ${ }^{76}$

Miembros: Michel Chevalier, presidente y François-Louis Bellaguet Disciplinas o Objetos de interés Actividades

Agricultura Seda, cacao, vainilla, cochinilla, tabaco, cera, algodón, guajolote, maíz, banana, yuca, especies de las plantas, reproducción, extensión de los terrenos de cultivo, gusano de seda chino, especies morera, trigo caña de azúcar, jardinería, flores, chinampas, consistencia y extensión de bosques

Industria Papel, agave mexicano, hilado, tejido, teñido, murex, Manufacturera variedades de aves arte plumario, reforestación, minas de oro y plata, explotación, principales yacimientos, métodos de extracción, herramientas, empleo de bronce, proceso de tallado en piedra, obsidiana, conocimientos mecánicos de los mexicanos, avances en orfebrería, pesca, perlas marinas, cachalote

${ }^{76}$ Archives..., p. 162-168. 
Cuadro 4. Cuarto Comité: Economía Política, Estadística, Trabajos Públicos y Cuestiones Administrativas (continuación)

Disciplinas o Objetos de interés Actividades

Comercio Sistemas de numeración y contabilidad, consideraciones y beneficios de comerciantes, extensión de operaciones, intercambios, diversidad étnica

Arquitectura Construcción de bóvedas y arcos, edificios monumentales, y trabajos públicos construcción con ladrillos, cerámica, tuberías para el agua, pirámides, construcción, revestimiento, variedades de cal, trabajos de irrigación, acueductos, puentes, tanque de agua, cisternas, salubridad en ciudades, Istmo de Tehuantepec, configuración del suelo, causas del despoblamiento de la Tierra Caliente.

Estadística Composición de la población, aumentos y disminuciones sucesivas, proporción de mezclas de razas: blanca, indígena, negra, malasia o china, mortalidad y nacimientos, estadísti$\mathrm{ca}$ industrial y comercial principalmente plata y oro

El hecho de que la CSM no haya tenido una verdadera comunicación y colaboración con la incipiente comunidad científica mexicana, ni una real interacción con la CSLAM, no significa que no haya contribuido al posterior desarrollo de algunas disciplinas científicas en México, si bien no en forma directa, sí como una influencia a manera de modelo de organización y planeación del trabajo.

Un dato que revela la importancia de la CSM es que, luego de la restauración de la república durante el gobierno de Porfirio Díaz, en 1883, cuando se crea la Comisión Científica Mexicana, ${ }^{77}$ dirigida por Alfonso Herrera Fernández, ésta aprovecha el modelo de la Commission Scientifique du Mexique en beneficio del conocimiento de los recursos naturales del país, ${ }^{78}$ lo que permite hablar de

${ }^{77}$ Memoria de la Secretaría de Fomento, "Comisión Científica”, Anexo núm. 43, en Informes correspondientes a los ańos de enero de 1883 a junio de 1885, vol. 4, México, Oficina Tipográfica de la Secretaría de Fomento, Memoria, 1887, 443-445.

${ }^{78}$ Ismael Ledesma-Mateos, "La introducción de los paradigmas de la biología en México y la obra de Alfonso L. Herrera” en Historia Mexicana, LII: 1(205), julio-septiembre, 2002, 201-240. 
una impronta de las actividades de dicha Comisión, a pesar de la interrupción de la aventura colonialista.

Debemos enfatizar que en el momento de la intervención francesa la condición de la ciencia mexicana se encontraba en una fase inicial, por lo que preguntarse si ¿las investigaciones francesas afectaron a las mexicanas?, no es pertinente en términos de una relación mecánica, aunque si en términos indirectos, lo cual implica fundamentalmente influencias bibliográficas. Así por ejemplo, la investigación fisiológica realizada en el porfiriato en el Instituto Médico Nacional, tiene un innegable corte derivado de la obra de Claude Bernard.

Cabe señalar que en el momento histórico en el que se dio la Intervención Francesa, está ocurriendo en Europa el surgimiento de los conceptos y teorías que conducirán a la constitución de la biología como ciencia ${ }^{79}$ lo cual implica el paso de la historia natural, acumulativa y descriptiva, a una nueva ciencia explicativa.

En Francia, un país con un enorme peso de la historia natural, es evidente que el énfasis de sus exploraciones, se pondría en la recolección de información descriptiva acerca de plantas, animales, minerales y descripciones geográficas.

Mientras tanto, en México la ciencia se encontraba en una situación francamente incipiente, por lo que las investigaciones francesas poco influenciaron a las mexicanas, pues lo que existía eran trabajos aislados de historia natural, y algunos notables en química y mineralogía. En el caso de la medicina, los textos utilizados en su enseńanza y en distintas disciplinas vinculadas a ella fueron fundamentalmente franceses, aunque la incorporación del conocimiento francés a la medicina había empezado años atrás a la intervención. ${ }^{80}$

${ }^{79}$ Ismael Ledesma-Mateos, "Biología: ¿Ciencia o naturalismo?”, Ciencia y Desarrollo, vol. xix, núm. 110, 1993, 70-77; Ismael Ledesma-Mateos, Historia de la biología, México, AGT Editor, 2000, 6-24.

${ }^{80}$ Lo anterior puede constatarse revisando los programas de estudio de la época, así como su bibliografía y el catálogo de la Biblioteca Nicolás de León de la Antigua Escuela de Medicina, ubicada en el Palacio de la Medicina de la unAM. 


\section{Conclusiones}

El gran proyecto de Napoleón III movilizó, en su momento a una infinidad de actores humanos y no humanos, sin alcanzar con ello los objetivos coloniales en su competencia con Inglaterra y con Estados Unidos. Con Inglaterra por el progreso alcanzado a partir de la revolución industrial y de la generalización de los "caminos de fierro", y con Estados Unidos por su impulsos expansionistas, su influencia sobre las jóvenes repúblicas latinoamericanas y su vocación protestante.

Pueden considerarse tres vertientes en el proceso de surgimiento de la Commission, la primera que sería la emulación de la comisión napoleónica en Egipto; la segunda, la certeza de que no hay trabajos sobre México más destacables que los elaborados por Humboldt, y que todo lo que se recabe deberá someterse a una rigurosa verificación científica; y la tercera, la gran curiosidad que les despertaba lo poco que conocían de México pero de cuya riqueza y diversidad tenían suficientes evidencias.

El llamado propósito civilizatorio de Francia, argumentado en la creación de la Commissión, implicaba la contribución al conocimiento del país en sus diversos aspectos: recursos naturales, cultura, geografía, infraestructura, industria etc., para tener éxito en la colonización del territorio si las condiciones políticas, geográficas, económicas y culturales lo permitían. Todo ello implicó una operación de traducción que involucra numerosas acciones que movilizaron a su vez a gran cantidad de actores humanos y no humanos, esto es, políticos, militares, científicos, recursos naturales o piezas arqueológicas entre otros.

Nos encontramos ante un proceso complejo y contradictorio donde intereses científicos se entremezclan con intereses imperialistas y coloniales, conjugados con una visión ideológica y mítica del territorio por dominar y sus riquezas. La perspectiva de la CSM desde París es conseguir que el mundo colonizado sea movilizado hacia ellos, sin que ocurra un doble desplazamiento con movilización hacia México, en tanto que persiste un menosprecio a las actividades de la incipiente comunidad científica mexicana, lo que impidió que 
se diera una verdadera colaboración, todo ello, aunado a la intervención brusca del proceso invasor, al momento del retiro de las tropas francesas.

En tanto, los integrantes de la CSLAM, actuaron más a la manera de integrantes de una corte imperial, buscando congraciarse con el nuevo régimen, sin un rigor científico y académico, lo que contribuyó a la incomunicación entre ambas comisiones. En ese contexto, el único esbozo de interacción se dio con en el seno de la comunidad médica, puesto que cuando se elaboran las instrucciones para el área correspondiente existía comunicación entre los médicos militares asentados en México y el barón Larrey, médico militar miembro del comité 1er Comité de la CSM y los integrantes de la sección sexta de la Comisión Científica, Literaria y Artística de México. La conformación de esta sección sexta es de gran relevancia porque tuvo continuidad después de la caída del Imperio y porque da cuenta del carácter conservador de la comunidad médica de ese tiempo.

A pesar del hincapié que los diferentes autores de las instrucciones hacen sobre la necesidad de la cooperación entre las diferentes disciplinas para lograr un conocimiento de conjunto, esto no aparece en el sucesivo desarrollo de las disciplinas y de las instituciones académicas en México, salvo algunas excepciones referentes a estudios fisiológicos, de historia natural o médicos, que obedecen más a influencias heurísticas, bibliográficas y hemerográficas, que al impacto de la Commission en las disciplinas científicas mexicanas. 
Anexo I

Composition de la Commission Scientifique, Littéraire et Artistique du Mexique ${ }^{81}$

\begin{tabular}{|c|c|}
\hline $1^{\mathrm{er}}$. section & Zoologie Et Botanique \\
\hline $2^{\mathrm{e}}$. section & Géologie Et Minéralogie \\
\hline $3^{\text {e }}$. section & Physique Et Chimie \\
\hline $4^{\mathrm{e}}$. section & Mathématiques Et Mécanique \\
\hline $5^{\mathrm{e}}$. section & $\begin{array}{l}\text { Astronomie, Physique Du Globe, Géographie, Hydrologie } \\
\text { Et Météorologie }\end{array}$ \\
\hline $6^{\mathrm{e}}$. section & $\begin{array}{l}\text { Médecine, Chirurgie, Hygiène, Médecine Vétérinaire, } \\
\text { Statistique Médicale, Matière Médicale, Anthropologie }\end{array}$ \\
\hline $7^{\mathrm{e}}$. section & Statistique Générale, Agriculture, Industrie, Commerce \\
\hline $8^{\mathrm{e}}$. section & Histoire Et Littérature \\
\hline $9^{\mathrm{e}}$. section & Ethnologie, Linguistique, Archéologie \\
\hline $10^{\mathrm{e}}$. section & $\begin{array}{l}\text { Beaux-Arts, Peinture, Sculpture, Architecture, Gravure, } \\
\text { Musique }\end{array}$ \\
\hline
\end{tabular}

Bureau

Président-Honoraire D. José Salazar Ilarregui,

Sous-Secrétaire D'état Du Fomento

Président

Le Colonel Doutrelaine Du Génie

Vice-Président

Sr D. José Fernando Ramirez

Secrétaire

Sr. D. Santiago Mendez

Idem

M. Le Capitaine Voisin De L'artillerie

Secrétaire Adjoint Et Conservateur

S. D.......... R....

Des Collections

Secrétaire Adjoint Et Bibliothécaire M. Le Capitaine Mathieu Du Génie

Trésorier

M Le Garde Marby Du Génie

Interprète $\quad$ M. Maillefar

${ }^{81}$ Archives Nationales (le site Paris) F/17/2909, dossier 1. 
$1^{\text {er }}$ Section Zoologie et botanique

Président M Le Lieutenant Colonel Boyco

Vice Présidents M Glennis Consul D'angleterre

Membres

Señor Don José Barragan

D Augustin Berroro

D Pio Bustamente

M Gouel Vétérinaire Du Quartier

Général

M Le Capitaine D’ Huars De

L'artillerie

S D Lauro Jimenez
M Le Commandant De Montarby M Le Capitaine Philippe Du Génie S D Santiago Ramirez

M Souvigny Vétérinaire De L'artillerie De La Garde

M Le Capitaine Seyev Du Génie

\section{$2^{\text {e }}$. Section Géologie et Minéralogie}

Président M Le Sous Colonel La Faille

Vice Présidents S D Antonio Del Castillo, et M Lanu Ingénieur Des Mines

Membres

S D Antonio Aguilar

M LE Lieutenant Baldy Du 2e Régi- M Le Capitaine Saudrey De ment de Zonavea

S D Sebastian Camacho

S D Prospero Goyzueta

\section{Le Docteur Maffre}

L'artillerie De La Garde

M Le Capitaine Vasseur De L'état

Major

\section{$3^{\text {e }}$. Section Physique et Chimie}

Président S D Ladislau Pafeur

Vice Présidents M Benoit Pharmacien En Chef, et M Le D Maffre

Membres

S D Sebastian Camacho

$S$ D Luis Espinosa

M Le Capitaine Leclerc De L'artillerie

S D Patricio Murphy
S D Léopold Rio De La Loza

S D Luis Varela 
4 ${ }^{\mathrm{e}}$. Section Mathématiques et Mécanique

Président S D Bruno Aguilar

Vice Présidents M Le Capitaine (ilegible)

$S \mathrm{D}$ Joaquin (ilegible)

Membres

S D Juan Barquera

M Emile Beaudouin

S D Francisco Garay

M Henri Griffon

S D Santago Jimenez

M Le Capitaine De Labitolle De

L'artillerie
M Le Capitaine Leclerc

S D Miguel Ponce De Leon

S D Manuel Rivera

$S$ D Remigio Sayago

$S$ D Francisco Somera

\section{5 . Section Astronomie, Physique Du Globe, Géographie,} Hydrologie, Météorologie

Président S D Jose Salazar Ilarregui

Vice Présidents S D Ignacio (ilegible), et M Salar Ancien Officier De Marine

Membres

S Général D Rafael Espinosa

S D Antonio Garcia Cubaz

M Le Capitaine Hallieu Du Génie

S D Francisco Jimenez

M Meziman Lieutenant De Vaisseau
M Le Capitaine De Mirabel De

Lartillerie De La Garde

M Le Capitaine Rousoelle De L'état

Major Général

S D Luis Varela

M Le Capitaine Wanca De L'état

Major Général

S D Ramon Ybarrola 
$6^{\mathrm{e}}$. Section Médecine, Chirurgie, Hygiéne, Médecine Vétérinaire, Statisque Médicale, Matière Médicale, Anthropologie

Président M Le Docteur Eichmann Médecin En Chef

Vice Présidents S Miguel Jimenez, et M Le Docteur Clément

Membres

S D Augustin Andrade

M Benoit Pharmacien En Chef

M Bergeyre Vétérinaire

$S$ D Ignacio Erazo

M Le Docteur Garrone

$S$ D Luis Hidalgo Carpio

M Le Docteur Hourcan Chirurgien

Major

M Leguistin Vétérinaire En Chef

S D Rafael Lucio

M Merchier Pharmacien Major
M Le Docteur Claudel Médecin

Major

M Le Docteur Coindet Chirurgien

Major

$S$ D Jose Maria Duran

$S$ D Montez De Oca

$S$ D Luis Muñoz

$S$ D Francisco Ortega

M Le Docteur Picard

M Le Docteur Schultze

S D Jose Maria Vertiz

$7^{\mathrm{e}}$. Sextion Statistique Générale, Agriculture, Commerce, Industrie, \& a

Président S D Urbano Fonseca

Vice Présidents M Frians Sous Intendant Militaire, et S D Manuel Pina

Y Cuevas

Membres

S D Jose Maria Andrade

$M$ Eustache Barron

$S$ D Jose Maria De Bassoco

$\mathrm{M}$ Benec Consul De ?????

M Le Capitaine Bage De Lártillerie

M Dantan

M Adrien Dast

M Doormann Consul De Hambourg

M Nathaniel Davidson

$S$ D Pedro Esenvero Y Echarruo

$S$ D Jose Maria Rincon Gallardo Marquis De Guadalupe
M Thomas Gillow

M Low

M Louën Payeur En Chef

M Amédée Lutton

$S$ D Santiago Mendez

M De Marcineau Chef De La

Légation

S D Eulalio Ortega

$S$ D Pedro Pasalagua

$S$ D Cayetano Rubio

S D Isidro De La Torre

$S$ D Romualdo Zamorra 


\section{$8^{\mathrm{e}}$. Section Histoire et Litérature}

Président M Mathieu De Fossey

Vice Président S D Jose Maria Larunza

Membres

S D Alexandre Arango Y Escandon

$S$ Doctor D Basilio Arillaga

$S$ D Francisco Demaccha

$S$ D Jose Roa Barcena

M De Barrea

M Le Lieutenant Cardin Du Génie
S D Jose Maria Lafragua

M Le Capitaine Mathieu Du Génie

$S$ D Jose Sebastian Segura

S D Jose Joaquin Garcia Ycazbalceta

$S$ D Jose Zorilla

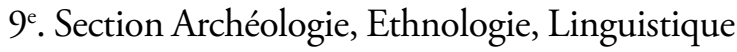

Président S D Jose Fernando Ramirez

Vice Président S D Francisco Pimentel

Membres

S D Faustino Galizia Chimalpopoca S D Manuel Erazo y Berra

10. Section Beaux-Arts, Sculpture, Architecture, Musique, Gravure, \& A

Président S D Lorenzo Hidalgo

Vice Présidents $M$ de Beance, et S D Pelegrin Clave

Membres

S D Amory Escandon

M Le Lieutenant Brunet De L'artillerie

S D Luis Campa

M Hippolite Carresse

M Le Docteur Clément

$S$ D Juan Cordero

$M$ Le Chef De Musique Demange Du $5^{\mathrm{e}}$.

M Le Lieutenant Dussanose De L'artillerie

$S$ D Antonio Gomez

M Le Capitaine Joly Du $12^{\mathrm{e}}$. Chasseurs A Cheval
S D Eleuterio Mendez

$S$ D Jose Maria Miranda

$S$ D Navalon

$S$ D Francisco Lizardi

$S$ D Piatti

M Pierson

M Reboul

M Sauvinet

S D Felipe Sojo

M Le Commandant Vasse De

L'artillerie

Transcripción: Françoise Marie Pierre Tual 


\section{BiBLIOHEMEROGRAFÍA}

AnCEAU, Eric, La France contemporaine: La France de 1848 a 1870. Entre ordre et mouvement, París, Librairie Générale Française, 2002.

Archives Nationales (le site Paris) F/17/2909

Azuela, Luz Fernanda, "La Sociedad Mexicana de Geografía y Estadística, la organización de la ciencia, la institucionalización de la geografía y la construcción del país en el siglo XIX", en Investigaciones Geográficas, unAM, México, diciembre, número 52, 2003, 153-166.

Brom, Juan, Esbozo de Historia de México, México, Grijalbo, 2007.

CALlOT, Jean-Pierre, "Les polytechniciens et l'aventure saint-simonienne”, en http://www.annales.org/archives/x/saintsimonisme. html

Dictionnaire de biographie française, 19 vols., París, Librairie Letouzey et Ané, 1936-2001.

Dictionnaire du Second Empire, Sous la direction de Jean Tulard de París, l'Institut, FAYARD, 1995, 1296.

El Pájaro Verde, tomo II, Ciudad de México, 1864.

Galeana, Patricia, "México: codiciado botín 1861-1863" en Revista Mexicana de Politica Exterior, nueva época, 40-41, México, Instituto Matías Romero de Estudios Diplomáticos, Secretaría de Relaciones Exteriores, 1993, 115-120.

, "Sueños imperiales" en Revista Mexicana de Politica Exterior, nueva época, 42, México, Instituto Matías Romero de Estudios Diplomáticos, Secretaría de Relaciones Exteriores, 1994, 81-88.

LATOur, Bruno, "Joliot: 1'histoire et la physique mêlées", en Michel Serres, dir., Élements d'Histoire des Sciences, París, Bordas, 1989. , La esperanza de Pandora. Ensayos sobre la realidad de los estudios de la ciencia, Barcelona, Gedisa, 2001.

LEDESMA-MATEOS, Ismael, "La introducción de los paradigmas de la biología en México y la obra de Alfonso L. Herrera”, en Historia Mexicana, LII, 1(205), julio-septiembre, 2002, 201-240.

LE Goff, Armelle, "La Commission de l'exploration scientifique de 
Mexique: Quelles archives aux Archives nationales?», Histoires(s) de l'Amerique Latine, vol. 3, 2009.

Maldonado-Koerdell, M., "La commission scientifique du Mexique, 1864-1869", en Memorias del Primer Coloquio Mexicano de Historia de la Ciencia, t. I, México, Sociedad Mexicana de Historia de la Ciencia y la Tecnología, 2-7 de septiembre de 1963, México, DF, 1964, 239-247.

Memoria de la Secretaría de Fomento, "Comisión Científica, Anexo núm. 43, en Informes correspondientes a los ańos de enero de 1883 a junio de 1885, vol. 4, México, Oficina Tipográfica de la Secretaría de Fomento, Memoria, 1887, 443-445.

Ministère de L'Instruction Publique, Archives de la Commission Scientifique du Mexique, t. I, París. Imprimerie Impériale, MDCCCLXV, 467 pp.

Nouvelle biographie générale: depuis le temps les plus reculés jusqu'à nos jours, 46 vols. París, F. Didot, 1857-1868.

Perez-Siller, Javier, "Presentación: un tema, una perspectiva, una problemática", en Javier Pérez-Siller, coord., México Francia. Memoria de una sensibilidad común. Siglos XIX-XX, México, Benemérita Universidad Autónoma de Puebla, El Colegio de San Luis, Centro Francés de Estudios Mexicanos y Centroamericanos, 1998, 11-12. Pichardo, Hugo, "La Comisión Científica francesa y sus exploraciones en el territorio insular mexicano, 1864-1867”, en Política y Cultura, otoño, núm. 016, 2001.

Prévost, Nadia, "Réévaluation de la 'Commission scientifique du Mexique’ à travers les dépêches du colonel Doutrelaine”, Colloque International Mémoire(s) d'ici et d'ailleurs. Hommage à Ernest-T. Hamy (1842-1908), C.E.R.C.L.E., HLLI, Université Du Littoral-Côte d'Opale, Boulogne-sur-Mer, France, 2008.

"La Commission scientifique du Mexique (1864-1867): un exemple de collaboration scientifique entre l'élite savante française et mexicaine?», en Revue d'Histoire des Sciences Humaines, Auxerre, núm. 19, 2008/2, 107-116.

SAldaÑa, Juan José, "La ciencia y la política en México (18501911)", en Ruy Pérez Tamayo, coord., Historia de la ciencia en México, FCE, Conaculta, México, 2010, 120-199. 
Schavelzon, Daniel, "La Comisión Científica Francesa a México (1864-1867) y el inicio de la arqueología en América”, en Sacarina, Arqueología y Etnografía Americana, vol. 3, año III, noviembre 2003, 313-322.

Service Historique de la Défense, G7, 206 , Diario del Imperio, 5 de julio de 1865.

Soberanis, Alberto, "La ciencia marcha bajo la égida de la guerra. Las relaciones científicas franco-mexicanas durante el imperio de Maximiliano (1864-1867)", en Revista Universidad de Guadalajara, Guadalajara, enero-febrero de 1995, 50-60.

"La expansión geográfica de la ciencia. Orígenes históricos de la Commission Scientifique du Mexique”, en Revista del Seminario de Historia Mexicana, Guadalajara, primera época, vol. 1, núm. 3, primavera de 1998, 9-75.

, "Sabios, militares y empresarios. Sansimonismo y exploración científica" en Javier Pérez-Siller y Chantal Cramaussel, coords., México-Francia. Memoria de una sensibilidad común. Siglos $X I X-X X$, México, Benemérita Universidad Autónoma de Puebla, El Colegio de San Luis, Centro Francés de Estudios Mexicanos y Centroamericanos, El Colegio de Michoacán, 2004.

TorT, Patrick, dir., Dictionaire du Darwinisme et de l'Evolution, vol. II, París, Presses Universitaires de France, 1996, 2957-2960.

FECHA DE RECEPCión DEL ARTículo: 4 de abril de 2011 FECHA DE RECEPCIÓN DE LA VERSIÓN FINAL: 31 de octubre de 2011 